\title{
Ezetimibe completely replaced LDL-apheresis for the treatment of familial hypercholesterolemia and coronary artery disease after $\mathrm{CABG}-\mathrm{A}$ case report
}

\author{
Ikuo Yokoyama ${ }^{1,2,3}$ \\ ${ }^{1}$ Department of Cardiovascular Medicine, Clinical Research Center, Sanno Medical Center Hospital, International University of \\ Health and Welfare, Tokyo, Japan \\ ${ }^{2}$ Department of Cardiovascular Medicine, Clinical Research Center, Sanno Hospital, International University of Health and Welfare, \\ Tokyo, Japan \\ ${ }^{3}$ Department of Cardiovascular Medicine, Department of Metabolic Diseases, Graduate School of Medicine University of Tokyo, \\ Tokyo, Japan \\ Email: yokochan-tky@umin.ac.jp
}

Received 7 November 2012; revised 8 December 2012; accepted 15 December 2012

\begin{abstract}
Intensive treatment of hyperlipidemia is an important factor in the prevention of cardiovascular disease. Among several therapies, statins are well recognized as playing a central role, although low density lipoprotein bound cholesterol-apheresis can be used to treat very severe cases of familial hypercholesterolemia. However, statins are not always effective on their own and, recently, ezetimibe has emerged as a unique antihypercholesterolemic drug that acts as a cholesterol transporter inhibitor; its role is only partially understood. I experienced rare case that appeared to benefit from ezetimibe therapy, and report them as they help increase our knowledge of this novel drug.
\end{abstract}

Keywords: Ezetimibe; Familial Hypercholesterolemia; Statins; LDL-Apheresis; Coronary Artery Disease

\section{INTRODUCTION}

The effectiveness of anti-hyperlidemia therapy for preventing cardiovascular events [1-5] and inducing the regression of coronary artery stenosis [6] has been demonstrated. Multicenter trials have indicated that hydroxymethylglutaryl coenzyme A reductase inhibitors, or statins, aid in preventing coronary artery disease (CAD) [2-5]. Furthermore, statin has been reported to be more effective for reducing the incidence of ischemic events than percutaneous transluminal coronary revascularisation therapy [7]. However, and despite the fact that statins are currently the mainstay of dyslipidemia management, their efficacy in preventing a cardiovascular event has limitations. This is because statins may exert adverse effects by restoring cholesterol levels via an enhance- ment of the reuptake of cholesterol and/or altered cholesterol derived from small intestines. Recently, ezetimibe has emerged as a new class of lipid-lowering drug, which acts via the inhibition of Niemann-Pick C1 Like 1 (NPC1L1), a protein that is localized in jejunal enterocytes [8]. Combination therapy of ezetimibe and statins has been shown to be highly effective in the treatment of hypercholesterolemia [9]. However, to date it has not been established whether ezetimibe combined with statin therapy has a much stronger effect than that of low density lipoprotein bound cholesterol (LDL)-apheresis, which is recognized as the most effective therapy for hyperlipidemia [10,11]. Recently, I experienced a rare case in which ezetimibe appeared to have an effective role, in place of LDL-apheresis, in a patient with familial hypercholesterolemia $(\mathrm{FH})$ and $\mathrm{CAD}$ who had undergone a coronary artery bypass graft (CABG). I report the case here.

\section{CASE}

This case concerned a 60-year-old male patient who was admitted to the University of Tokyo Hospital from his local clinic to treat FH. As the patient had a family history of severe hypercholesterolemia (3 of 5 brothers had hypercholesterolemia) and CAD (one brother had CAD), he was tested for the existence of CAD using rest to dipyridamole stress myocardial perfusion positron emission tomography (PET) (Headtome IV Shimadzu Corp \& Ltd., Kyoto, Japan) and ${ }^{13} \mathrm{~N}$-ammonia. The PET study revealed that this patient was at high risk for CAD, and because a subsequent coronary angiography showed the presence of 3-vessel disease, he underwent CABG. After CABG, the patient was treated with pravastatin $(20 \mathrm{mg})$ for the secondary prevention of CAD. However, the pravastatin failed to treat his hypercholesterolemia ap- 
propriately, and we therefore decided to treat it using LDL-apheresis therapy. Before the initiation of LDLapheresis, total cholesterol (TC) was $351 \mathrm{mg} / \mathrm{dl}$, high density lipoprotein bound cholesterol (HDL) was 45 $\mathrm{mg} / \mathrm{dl}$, calculated low density lipoprotein bound cholesterol (cLDL) was $274 \mathrm{mg} / \mathrm{dl}$, and triglycerides (TG) were $113 \mathrm{mg} / \mathrm{dl}$. After treatment with pravastatin (20 mg/day) and eicosapentaenoic acid (EPA) $1800 \mathrm{mg} / \mathrm{day}$, TC, HDL and cLDL had decreased to $309 \mathrm{mg} / \mathrm{dl}, 40 \mathrm{mg} / \mathrm{dl}$, and $222 \mathrm{mg} / \mathrm{dl}$, respectively, and TG had increased to $188 \mathrm{mg} / \mathrm{dl}$. Just before the initiation of LDL-apheresis, the corresponding values were: TC $284 \mathrm{mg} / \mathrm{dl}$, HDL 35 $\mathrm{mg} / \mathrm{dl}$, cLDL $211 \mathrm{mg} / \mathrm{dl}$ and TG $194 \mathrm{mg} / \mathrm{dl}$. Just after the LDL-apheresis, TC had declined to $75 \mathrm{mg} / \mathrm{dl}$, as had cLDL (47.4 mg/dl), HDL (23 mg/dl), and TG (23 mg/dl). However, one week after the LDL-apheresis, TC had increased to $163 \mathrm{mg} / \mathrm{dl}$, as had HDL (30 mg/dl), cLDL (103 mg/dl), and TG (55 mg/dl). Ten days after the third LDL-apheresis, TC had increased (250 mg/dl), HDL had decreased (38 mg/dl), cLDL had increased (190.4 mg/dl), and TG had increased (108 mg/dl). Therefore, it was difficult to lower the cLDL consistently below $100 \mathrm{mg} / \mathrm{dl}$ in this patient, even when he was treated with both LDL-apheresis and other statins such as furuvastatin (80 $\mathrm{mg} /$ day), atorvastatin (40 mg/day) and rosvastatin (7.5 15 mg/day) (Figure 1).

Because of these results, on 21 Jan 2008, we decided to add ezetimibe (10 mg). After combination therapy with ezetimibe, rosvastatin (15 mg/day), EPA (2700 $\mathrm{mg} /$ day) and LDL-apheresis, his cLDL was maintained consistently below $100 \mathrm{mg} / \mathrm{dl}$. In addition, TC was maintained consistently below $160 \mathrm{mg} / \mathrm{dl}$ and TG below 75 $\mathrm{mg} / \mathrm{dl}$, even when blood sampling was undertaken 2-3 weeks after the LDL-apheresis. Because of these good results, we decided to end the patient's LDL-apheresis therapy on 1 Sep. 2008 without changing medications. Four weeks later, the lipid fraction parameters were: TC $126 \mathrm{mg} / \mathrm{dl}$, cLDL $79 \mathrm{mg} / \mathrm{dl}$, HDL $37.0 \mathrm{mg} / \mathrm{dl}$, and TG 50 $\mathrm{mg} / \mathrm{dl}$. Furthermore, the cLDL was kept approximately under $100 \mathrm{mg} / \mathrm{dl}$ and there were no CAD and/or cerebrovascular events between 1 Sep. 2008 and 4 Oct. 2010 (TC $131 \mathrm{mg} / \mathrm{dl}$, cLDL $79.3 \mathrm{mg} / \mathrm{dl}$, HDL $32.0 \mathrm{mg} / \mathrm{dl}$, and TG $59 \mathrm{mg} / \mathrm{dl}$ ), during which period the patient had been maintained on rosvastatin (15 mg/day), ezetimibe (10 $\mathrm{mg} /$ day) and EPA (2700 mg/day; this dose was initiated before the start of ezetimibe) (Figure 1). The average TC after stopping of LDL-apheresis (139.3 $\pm 10.3 \mathrm{mg} / \mathrm{dl})$ was similar to that during LDL-apheresis plus ezetimibe $(137.3 \pm 7.73 \mathrm{mg} / \mathrm{dl})$, and significantly lower than that before the initiation of ezetimibe $(189.9 \pm 32.4 \mathrm{mg} / \mathrm{dl})$; average cLDL after stopping of LDL-apheresis (91.7 \pm $9.31 \mathrm{mg} / \mathrm{dl})$ was similar to that during LDL-apheresis plus ezetimibe $(93.8 \pm 7.37 \mathrm{mg} / \mathrm{dl})$ and notably lower than that before initiation of ezetimibe (133.2 \pm 28.2 $\mathrm{mg} / \mathrm{dl}$ ); average HDL after stopping of LDL-apheresis

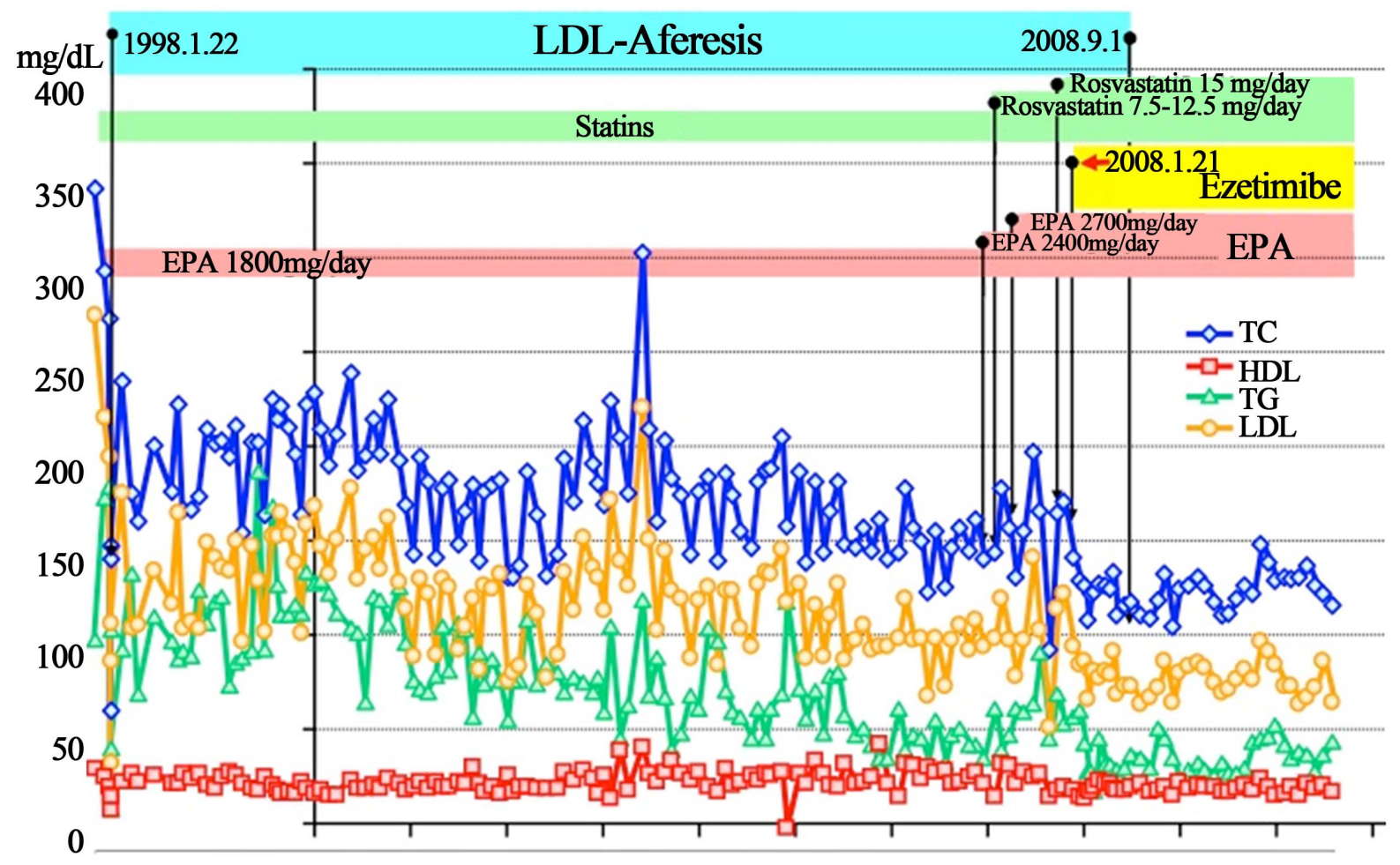

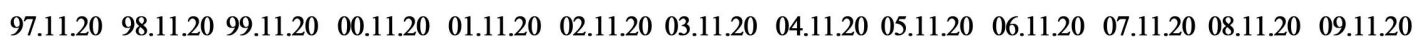

Figure 1. Clinical course of the case: the patient's plasma lipid fractions before and after ezetimibe therapy. 
Table 1. Plasma lipids fractions in the case: during LDL-apheresis therapy with statins before and after ezetimibe, and after stopping LDL-apheresis. TC: total cholesterol; HDL: high density lipoprotein bound cholesterol; cLDL: calculated low density lipoprotein bound cholesterol; TG: triglycerides.

\begin{tabular}{lcccc}
\hline \multicolumn{1}{c}{ Treatment regimen } & TC (mg/dl) & HDL (mg/dl) & TG (mg/dl) & cLDL (mg/dl) \\
\hline During LDL-apheresis plus statins (before initiation of ezetimibe) & $189.9 \pm 32.4$ & $37.9 \pm 6.02$ & $93.8 \pm 30.4$ & $133.2 \pm 28.2$ \\
During LDL-apheresis plus ezetimibe and rosvastatin & $137.3 \pm 7.73$ & $33.9 \pm 2.84$ & $48.6 \pm 11.3$ & $93.8 \pm 7.37$ \\
After stopping LDL-apheresis. Rosvastatin and ezetimibe only & $139.3 \pm 10.3$ & $34.2 \pm 2.27$ & $50.8 \pm 8.47$ & $91.7 \pm 9.31$ \\
\hline
\end{tabular}

$(34.2 \pm 2.27 \mathrm{mg} / \mathrm{dl})$ was similar to that during LDLapheresis plus ezetimibe (33.9 $\pm 2.84 \mathrm{mg} / \mathrm{dl})$, and tended to be lower than that before initiation of ezetimibe treatment (37.9 $\pm 6.02 \mathrm{mg} / \mathrm{dl})$; average TG after stopping of LDL-apheresis $(50.8 \pm 8.47 \mathrm{mg} / \mathrm{dl})$ was similar to that during LDL-apheresis plus ezetimibe $(48.6 \pm 11.3 \mathrm{mg} / \mathrm{dl})$ and notably lower than that before initiation of ezetimibe $(93.8 \pm 30.4 \mathrm{mg} / \mathrm{dl})$ (Table 1). During all of the 13-year follow-up period, creatine phosphokinase (CK) was continuously almost within normal limits under all types of therapy except for one mild case (CK less than 260 mg/dl). Liver enzymes such as ALT and AST were within normal range during ezetimibe therapy and almost within normal limits during all of the follow-up period, except for the period during which the patient was treated with $40 \mathrm{mg}$ of atorvastatin.

\section{DISCUSSION}

In this case, levels of TC, cLDL, and TG returned very quickly to those recorded at baseline one week after LDL-apheresis. Moreover, replacing LDL-apheresis with ezetimibe notably decreased TC and cLDL to the levels that are required for the secondary prevention of CAD after CABG; this was not achieved with LDL-apheresis and statins. In addition, the level of TG was also notably decreased by approximately 54\% compared with that seen before the initiation of ezetimibe therapy. Therefore, it appears that, in addition to reducing the level of the cholesterol compounds absorbed from the small intestines, ezetimibe also has an effect in reducing TG via unknown but important mechanisms in small intestines.

At this stage, we can only speculate on the mechanisms involved in the outcome of this case in which ezetimibe completely replaced LDL-apheresis. Firstly, our results could be explained by the over expression of NPC1L1 messenger RNA, due to the very high dose of rosvastatin used and aggressive affect of LDL-apheresis that decreased LDL level acutely, leading to up regulation of ATP-binding cassette transporters G5 and G8 (ABCG5 and ABCG8), which would in turn increase cholesterol extraction in response to inhibitory effect of ezetimibe to NPC1L1; a negative correlation has been found between NPC1L1 and ABCG5 and ABCG8 [12].

This case provides strong evidence that replacing
LDL-apheresis and statin combination therapy with ezetimibe and statin combination therapy would achieve better results in the treatment of hypercholesterolemia. We would therefore like to propose that, in patients with severe hyperlipidemia, LDL-apheresis should be replaced by ezetimibe.

Finally, the results obtained in this study might give great hope and encouragement to patients with $\mathrm{FH}$ or severe hypercholesterolemia or severe mixed combined hyperlipidemia who are currently treated with LDLapheresis.

\section{REFERENCES}

[1] De Lorgeril, M., Renaud, S., Mamelle, N., et al. (1994) Mediterranean alpha-linolenic acid-rich diet in secondary prevention of coronary heart disease. Lancet, 343, 14541459. doi:10.1016/S0140-6736(94)92580-1

[2] Scandinavian Survival Study Group (1994) Randomised trial of cholesterol lowering in 4444 patients with coronary heart disease. Lancet, 344, 1383-1389.

[3] Shepherd, J., Cobbe, S.M., Ford, I., et al. (1995) Prevention of coronary heart disease with pravastatin in men with hypercholesterolemia. West of Scotland Coronary Prevention Study Group. New England Journal of Medicine, 333, 1301-1307. doi:10.1056/NEJM199511163332001

[4] The Long-Term Intervention with Pravastatin in Ischaemic Disease (LIPID) Study Group (1998) Prevention of cardiovascular events and death with pravastatin in patients with coronary heart disease and a broad range of initial cholesterol levels. New England Journal of Medicine, 339, 1349-1357. doi:10.1056/NEJM199811053391902

[5] Lewis, S.J., Sacks, F.M., Mitchell, J.S., et al. (1998) Effect of pravastatin on cardiovascular events in women after myocardial infarction: The cholesterol and recurrent events (CARE) trial. Journal of the American College of Cardiology, 32, 140-146. doi:10.1016/S0735-1097(98)00202-2

[6] Gould, K.L., Ornish, D., Kirkeeide, R., et al. (1992) Improved stenosis geometry by quantitative coronary arteriography after vigorous risk factor modification. American Journal of Cardiology, 69, 845-853. doi:10.1016/0002-9149(92)90781-S

[7] Pitt, B., Waters, D., Brown, W.V., et al. (1999) Aggres- 
sive lipid-lowering therapy compared with angioplasty in stable coronary artery disease. Atorvastatin versus revascularization treatment investigators. New England Journal of Medicine, 341, 70-76.

doi:10.1056/NEJM199907083410202

[8] Ge, L., Wang, J., Qi, W., et al. (2008) The cholesterol absorption inhibitor ezetimibe acts by blocking the sterolinduced internalization of NPC1L1. Cell Metabolism, 7, 508-519. doi:10.1016/j.cmet.2008.04.001

[9] Stein, E., Stender, S., Mata, P., et al. (2004) Achieving lipoprotein goals in patients at high risk with severe hypercholesterolemia: Efficacy and safety of ezetimibe coadministered with atorvastatin. American Heart Journal, 148, 447-455. doi:10.1016/j.ahj.2004.03.052

[10] Gordon, B.R., Kelsey, S.F., Dau, P.C., et al. (1998) Long-term effects of low-density lipoprotein apheresis using an automated dextran sulfate cellulose adsorption system. Liposorber Study Group. American Journal of Cardiology, 81, 407-411. doi:10.1016/S0002-9149(97)00947-8

[11] Thompson, G.R., Barbir, M., Davies, D., et al. (2010) Efficacy criteria and cholesterol targets for LDL apheresis. Atherosclerosis, 208, 317-321. doi:10.1016/j.atherosclerosis.2009.06.010

[12] Lally, S., Tan, C.Y., Owens, D. and Tomkin, G.H. (2006) Messenger RNA levels of genes involved in dysregulation of postprandial lipoproteins in type 2 diabetes: The role of Niemann-Pick C1-like 1, ATP-binding cassette, transporters G5 and G8, and of microsomal triglyceride transfer protein. Diabetologia, 49, 1008-1016. doi:10.1007/s00125-006-0177-8 